\title{
Um meio de aproximação da família à escola através da matemática
}

\author{
One way to approach family to school through mathematics
}

\author{
Sofia Ramos \& Lina Fonseca \\ Instituto Politécnico de Viana do Castelo
}

\begin{abstract}
Resumo
A família e a escola devem proporcionar às crianças ambientes de aprendizagem diferenciados, mas em conexão. A relação efetiva entre estas instâncias educativas é promotora de sucesso escolar, particularmente importante quando nos referimos à matemática, visto que esta disciplina é muitas vezes "pouco amada". Ainda se manifesta a conceção de que se os pais não gostaram de matemática é natural que os filhos também não gostem. Para tentar romper este ciclo importa que escola e família congreguem esforços para motivar os alunos para a aprendizagem da matemática e assim ultrapassar obstáculos.

Palavras chave: relação escola-família, trabalhos de casa, desafios matemáticos, criatividade.
\end{abstract}

\begin{abstract}
Family and school should provide children with necessarily different, but connected, learning environments. The effective relationship between these educational instances promotes school success. The quality of this relationship is particularly important when referring to mathematics. This school content is often "unloved" and the conception that "if parents didn't like mathematics is naturally accepted that children will not like it” is still alive. To try to break this cycle is important that school and family joint forces together to motivate pupils to learn mathematics and to overcome difficulties. Keywords: familyschool partnership, homework, mathematical challenges, creativity.
\end{abstract}

\section{Introdução}

A relação entre a família e a escola é determinante para o sucesso dos alunos (Christenson \& Sheridan, 2001) e nem sempre esta relação se intensifica pelos melhores motivos. Muitos encarregados de educação apenas procuram a escola quando existem problemas com os seus educandos, ou são convidados a visitá-la devido a alguma queixa que a escola tenha relativamente aos alunos, o que, no dizer de César (2012), não retrata um envolvimento real. Desenvolvese assim uma díade escola-família revestida de carga negativa. A preocupação da família prende-se muitas vezes com o produto (resultados das avaliações finais) e não com o processo de aprendizagem. Com saber se os trabalhos de casa diários estão feitos, desconhecendo o seu conteúdo, pois esta responsabilidade, em muitos casos, é transferida para centros de estudo ou explicadores.

Numa turma do $4^{\circ}$ ano de escolaridade, com alunos de 9 e 10 anos, detetou-se uma participação pouco significativa das famílias na escola e no acompanhamento do percurso académico dos alunos. A preocupação da família centrava-se principalmente na preparação para os exames nacionais, que os alunos deveriam realizar no final do ano letivo. Para além disso, em sala de aula, o trabalho na área de matemática baseava-se muito na exploração do manual escolar.

Algumas questões começaram a tomar forma: Como agir para alterar esta situação? Como envolver família e alunos nas questões escolares? Como desafiar os alunos? Como alterar as conceções negativas sobre a matemática?

No sentido de aprofundar conhecimento sobre esta temática e procurar ultrapassar alguns dos obstáculos detetados foi desenhado um estudo que pretendeu desenvolver a relação escola-família potenciando a atração pela matemática e a criatividade dos alunos através de desafios semanais. Para orientar o estudo foram definidas as seguintes questões: (a) A resolução cooperativa de desafios matemáticos semanais potencia a relação escola-família? (b) A resolução de desafios matemáticos semanais promove a atração dos alunos pela matemática e desenvolve a sua criatividade? (b1) Qual o grau de implicação dos alunos com os desafios matemáticos? (b2) Que aspetos da criatividade demonstram os alunos na resolução dos desafios matemáticos?

\section{Relação Escola-Família}

A escola tem sido designada ultimamente como família educativa pelo suporte que é para as famílias na educação dos seus filhos (Almeida, 2005) colocando-se, por vezes, na escola expectativas excessivas relativamente à sua ação (César, 2012; Roy, 1997). Inversamente, também a escola tem dificuldade em entender a complexidade crescente da tarefa das famílias na sociedade atual, o que dificulta o vínculo entre estas instâncias educativas (César, 2012, Roy, 1997), apesar de cada parte reconhecer a essencialidade da ação da outra no desenvolvimento das crianças.

A família é meio privilegiado de pedagogia, por ser o primeiro universo, a primeira sociedade que a criança conhece, na qual se insere, a partir da qual se conhece e começa a construir a sua personalidade. As relações de afeto e proximidade que se devem estabelecer na família 
favorecem a sua ação pedagógica e de transformação das crianças em seres culturais, ficando a escola destinada a aprendizagens mais formais, sem que isso retire afetividade à relação a estabelecer com as crianças. Estas instituições têm missões educativas diferentes, mas complementares (Roy, 1997), visto que cada uma deve potenciar a ação da outra junto da criança.

Callender \& Hansen (2004) e Epstein (2002) defendem a necessidade de grande flexibilidade por parte das duas instituições, sendo sensíveis às especificidades uma da outra, desenvolvendo um clima de entendimento, aceitação de diferenças e valorização dos distintos papéis, partilhando responsabilidades e promovendo efetivamente um trabalho cooperativo (Callender \& Hansen, 2004; Christenson \& Sheridan, 2001) que resultará em benefício da criança, sem que memórias de experiências mal sucedidas a possam prejudicar.

Há diversas situações que fomentam o envolvimento da família na escola e na educação das crianças. Assim, as escolas devem proporcionar uma variedade de possibilidades e oportunidades para que este aconteça efetivamente, já que "as influências educativas da família e da escola serão tanto mais fortes, quanto mais essas instituições estiverem unidas e orientadas, na mesma direção” (Roy, 1997, p.163) favorecendo o sucesso escolar dos alunos. No entanto, diversos estudos indicam que a cultura escolar não se encontrava nem se encontra, a maioria das vezes, preparada para receber realmente as famílias e permitir a sua participação ativa (César, 2012). Na prática, não estão criadas condições para que a escola possa receber os pais (César, 2012). Os professores não dispõem de tempo para atendê-los, conhecendo pouco da vida de cada aluno e suas famílias, devido ao crescente de burocracia a que têm de responder. Por estas razões, o contacto com os familiares remete-se a práticas ritualizadas em cada período escolar, como reuniões de pais onde se focam, principalmente, os resultados conseguidos pelos alunos (César, 2012), sem a oportunidade de cada aluno e família serem vistos como casos específicos que são. Este aspeto retrai algumas famílias de potenciarem a sua relação com a escola, principalmente aquelas que poderiam beneficiar mais desta relação, famílias cuja formação académica é mais reduzida e que se sentem inibidas e "intimidadas pelo poder, nomeadamente de argumentação, dos professores.” (César, 2012, p.261). De modo a valorizar a aprendizagem e o conhecimento urge atuar tendo em vista o sucesso escolar dos atuais alunos e a sua envolvência com a escola, conseguindose o empoderamento de gerações futuras, como meio de garantir uma "participação ao longo da vida, não só dos próprios, mas também dos seus descendentes, ou seja, é um fenómeno de inclusão e valorização, ou de exclusão e discriminação negativa, que tem impactes transgeracionais.” (César, 2012, p.261).

\section{Os trabalhos de casa}

Existem vários entendimentos em relação à pertinência dos trabalhos de casa, normalmente designados por TPC. Apesar de diferentes correntes de entendimento sobre a sua relevância para a aprendizagem dos alunos, a prescrição de trabalhos a realizar após o horário letivo, feita pelos professores, tornou-se, ao longo dos tempos, uma prática quase ritualizada (Gil \& Schlossman, 2003; Henriques, 2006). A primeira intenção - promover um maior sucesso dos alunos -, perde-se muitas vezes em práticas desajustadas e que produzem efeitos adversos (Henriques, 2006). Outro objetivo seria levar a escola para fora dela, por forma a permitir às famílias contactar com o trabalho escolar, mas a autora refere que o TPC enviado nem sempre retrata as práticas de sala de aula, não podendo, nestes casos, informar adequadamente as famílias do nível de desenvolvimento dos alunos e do que realizam na escola. Desta forma, pode contribuir para desenvolver um ambiente de avaliação mútua, gerador de conflitos que enfraquecem a relação E-F.

A investigação realizada sobre o tema mostra que as principais dificuldades das famílias, na ajuda ao TPC dos filhos, dizem respeito à matemática, devido às suas conceções enquanto aprendentes deste assunto, mas também, às constantes mudanças curriculares (César, 2012). Apesar de geralmente nas famílias portuguesas ser a mãe o membro mais envolvido na supervisão do TPC (Moreno, Fonseca \& Gonçalves, 2012; César, 2012), existe na matemática uma outra hierarquia de validação de conhecimentos: os irmãos mais velhos são os primeiros a quem os alunos recorrem, pois foram eles que contactaram com a matemática e seus métodos de ensino mais recentemente. Para superar estes problemas há famílias que recorrem a atores periféricos, centros de estudo e explicadores, delegando em terceiros o apoio extraescolar das crianças.

Face a esta problemática percebe-se a urgência em encontrar respostas que aproximem as famílias dos alunos na resolução dos TPC, pois estes momentos só se tornarão de efetivo envolvimento entre pais e filhos e entre estes e a escola, se houver um entendimento comum desta prática e se os pais se sentirem apoiados nesta tarefa.

\section{Desafios matemáticos}

A importância do desafio na aprendizagem da Matemática tem sido alvo de atenção, pois as tarefas desafiadoras têm-se mostrado ferramentas enriquecedoras das aprendizagens matemáticas (Taylor, 2009). Apesar desta constatação, as práticas demonstram que os alunos são muitas vezes desafiados, sim, mas através de competições que ocorrem fora do contexto da sala de aula. Este clima desafiador é desenvolvido, mas de uma forma desligada das aprendizagens formais, talvez devido às limitações do tempo destinado às práticas letivas a par da extensão de conteúdos do programa (Taylor, 2009).

A escolha das tarefas é uma ação que cabe ao professor, sendo de crucial importância pela potencialidade que as tarefas apresentam na promoção de uma dinâmica desafiadora e ajustada às especificidades dos diferentes alunos que integram uma sala de aula (Ponte, 2009). Mas para além da escolha de tarefas motivadoras e diversificadas, o modo como estas são introduzidas e exploradas em sala de aula é 
essencial para que os alunos se envolvam na sua resolução com motivação (Ponte, 2009), promovendo-se a aprendizagem da matemática com compreensão.

Ponte (2005) classifica as tarefas matemáticas segundo duas dimensões: nível de estruturação e o grau de dificuldade/desafio que representam para o resolvedor. Cruzando destas características, as tarefas podem classificar-se como: exercício, problema, exploração, ou investigação. As duas primeiras são tarefas mais fechadas, sendo os problemas entendidos como mais complexos. As duas últimas são tarefas mais abertas, sendo as investigações mais complexas, podendo ser também mais longas no tempo. Estes tipos de tarefas não esgotam a tipologia a apresentar aos alunos em sala de aula - dimensões como a duração da tarefa, o contexto ou a temática podem permitir apresentar, por exemplo, projetos ou jogos.

Vários autores concordam que a resolução de problemas favorece, para além do desenvolvimento do raciocínio lógico, a persistência e envolvimento dos alunos na busca de soluções para situações diversas, dentro e fora da sala de aula, tal como o pensamento divergente e a sua criatividade (Pehkonen, 1997).

\section{Criatividade}

Ser criativo é uma capacidade muito valorizada hoje em dia, pois entende-se que alguém criativo estará mais bem preparado para se adaptar às rápidas mudanças com que o mundo nos presenteia a todo o momento. Por esta razão, a criatividade tem sido alvo de estudo nas diferentes áreas do ensino, considerando-se uma capacidade importante que deve ser desenvolvida nas escolas. Apesar desta constatação há atitudes que vão em contra mão com o desenvolvimento desta capacidade. Em casa e na escola, a criança é desde cedo confrontada com um conjunto de regras e proibições que a formatam socialmente e, pouco a pouco, a fazem desistir de arriscar (Alencar, 1989). Estas construções sociais iniciais surgem como a primeira barreira ao desenvolvimento da criatividade da criança, à sua coragem para criar algo novo, para inovar. Face a este panorama inibidor da criatividade, e como esta é uma capacidade que pode ser desenvolvida (Sheffield, 2009), é necessário mudar o cenário futuro das escolas, não bastando continuar a estimular os alunos em atividades pontuais, mas a mudança tem de afetar transversalmente a escola e todos os que nela participam.

As abordagens mais significativas no ensino da criatividade são "aquelas que envolvem funções cognitivas e emocionais, estrutura e motivação adequadas e dão oportunidade de envolvimento, prática e interação do aluno com professores e outros alunos.” (Torrance \& Torrance, 1974, p.45).

O desenvolvimento da criatividade pode ser intencional e, para tal, o professor deve atuar de modo a favorecer a autoimagem dos alunos, as suas conceções sobre si próprios (Sheffield, 2009).

Organizando um ambiente de sala de aula em que o aluno esteja disponível para explorar, procurar novas ideias, transformar, avaliar, argumentar e defendê-las, promovem-se momentos de sucesso por parte de todos, tornando os alunos mais confiantes para se libertar e demonstrar as próprias ideias. Isto é fundamental para o desenvolvimento da sua criatividade (Alencar, 1991).

Particularmente na área de matemática, a criatividade foi, durante muito tempo, negligenciada, e ainda o é, por muitos professores, apesar da atividade de fazer matemática estar repleta de ações criativas (Movshovitz-Hadar \& Kleiner, 2009).

A criatividade matemática envolve o pensamento divergente e manifesta-se em três dimensões: a fluência, flexibilidade e originalidade, relacionando-se com a resolução e formulação de problemas (Sheffield, 2009; Vale, Pimentel, Cabrita, Barbosa, \& Fonseca, 2012)

O pensamento divergente está associado a processos criativos porque envolve a imaginação e criação de múltiplas soluções para um mesmo problema. A fluência é a capacidade de gerar o maior número de ideias, respostas corretas e métodos para resolver um determinado problema. Para além disso, também aqui é considerado o número de novas questões formuladas a partir da primeira e a continuidade e associações estabelecidas entre as ideias geradas. A flexibilidade é a habilidade de apresentar distintos contextos ou categorias diferentes de resposta, métodos e questões. Esta capacidade permite ao resolvedor lucrar de flexibilidade de pensamento - mudar ou adaptar as suas ideias perante um mesmo problema. A originalidade é a capacidade de criar algo totalmente novo, que não é usual - quer ao nível de soluções, métodos, ou questões. Segundo Sheffield (2009) a criatividade dos alunos pode ainda ser avaliada segundo a profundidade de conhecimento que revelam nas suas respostas.

\section{Metodologia}

Face ao exposto, ao objetivo e questões a que se pretendia responder, desenvolveu-se um estudo de natureza qualitativa, com um design de estudo de caso.

Os participantes constituíam uma turma de 24 alunos do $4^{\circ}$ ano de escolaridade ( 9 anos de idade).

Semanalmente foi proposto um desafio matemático que deveria ser resolvido, ao fim de semana, necessariamente com a família. Neste estudo o conceito de família é lato. Os familiares com os quais as crianças podiam resolver os desafios eram: mãe, pai, irmãos, avós, tios, primos, padrinhos, etc. Para divulgar as resoluções criou-se um blogue ${ }^{1}$, meio que permitiu que alunos e famílias tivessem acesso a todas as contribuições e vissem as suas propostas divulgadas.

Para além dos desafios semanais, a recolha de dados contou com observação participante, registos áudio e fotográficos e inquéritos por questionário (alunos e famílias) e entrevistas (pais e professora).

Como a intervenção tinha por objetivo desenvolver a relação escola-família, potenciando a atração pela matemática, e desenvolver a criatividade dos alunos, através da resolução cooperativa (criança - familiares) de desafios semanais foram aplicados 11 desafios, cujos temas matemáticos e extra matemáticos estavam situados nas aprendizagens realizadas na escola. Serviam como ponto de partida, para o trabalho da semana seguinte, quer este fosse de iniciação a novos

${ }^{1}$ http://desafiartenamatematica.blogspot.pt/ 
temas ou de reforço a temas já abordados. Na semana seguinte os desafios e as propostas de resolução eram discutidos em grande grupo na sala de aula.

Os desafios foram apresentados na tarde de sextafeira, seguindo por exemplo a forma de problemas tipo puzzle, ou de mensagens escondidas, de modo a quebrar com a tradicional imagem do TPC. Pretendeu-se que fossem acessíveis a todas as crianças e famílias e que pudessem ser resolvidos de diferentes modos, para que o grau de exigência não afastasse os menos preparados nesta área e permitisse mostrar que todos podem enfrentar questões de matemática. Os desafios relacionavam-se com outros assuntos curriculares e aspetos do dia a dia, procurando mostrar que a matemática não é uma ilha, mas que está disseminada à nossa volta.

\section{Desafio 11}

Mostra-se a seguir o último desafio apresentado e duas propostas de resolução. ${ }^{2}$

Este pretendia trabalhar as frações e simultaneamente coligir todos os desafios anteriormente apresentados.

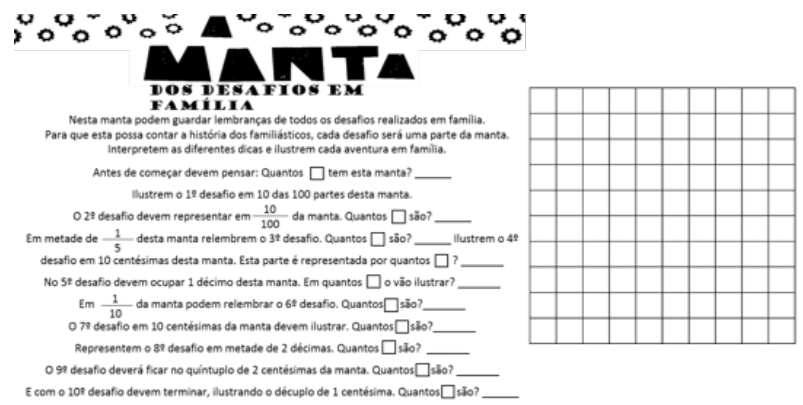

Figura 1. Apresentação do Desafio 11.

Os alunos representaram os desafios realizados de modos muito diversificados, como ilustra a Figura 2.

A quase totalidade das crianças identificou cada uma das frações envolvidas como sendo $1 / 10$ da manta $e$ representou sempre do mesmo modo, em linha, todos os desafios. No entanto, algumas crianças escolheram motivos alusivos ao conteúdo do desafio, revelando profundidade do conhecimento matemático nele trabalhado (Figura 2 - à esquerda). A sua pormenorizada representação foi considerada original.

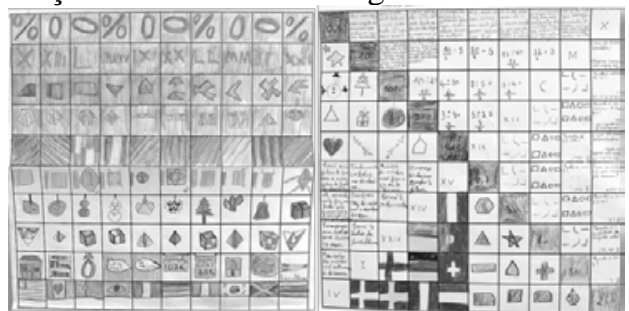

Figura 2. Exemplos de resolução do Desafio 11.

Outras crianças revelaram-se mais criativas no modo como organizaram a décima parte da manta. Foram fluentes pois representaram de vários modos os diferentes desafios e flexíveis pois mudaram de representação (exemplo: diagonal, triangular) - Figura 2

\footnotetext{
${ }^{2}$ Os restantes desafios e resoluções estão disponíveis em: http://desafiartenamatematica.blogspot.pt/
}

(à direita). Foram também originais porque encontraram um modo único de representação.

A este desafio responderam 13 famílias, com 9 resultados corretos, sendo 5 deles representações originais.

\section{Algumas conclusões}

Pela observação da dinâmica implementada, dos resultados partilhados pelos participantes no blogue e em sala de aula e através dos resultados das entrevistas é possível perceber-se a influência dos desafios semanais na relação escola-família. Desta forma, dar-se-ão conta destas evidências respondendo-se às questões que orientaram esta investigação.

Os desafios matemáticos conseguiram trazer mais os pais à escola, mesmo que isto acontecesse de forma virtual, através do e-mail e das visitas ao blogue onde eram partilhados todos os desafios. É prova disto o envolvimento de famílias que até aí não estabeleciam qualquer contacto com a professora titular de turma.

No caso de famílias que manifestavam já algum grau de envolvimento com a escola, os desafios matemáticos potenciaram-no, tornando esta relação mais produtiva. Criaram-se desta forma laços mais específicos com a matemática, aproximando-se alunos e familiares, de forma motivada, de uma matemática mais desafiadora e divertida. “Assim a matemática é mais divertida, gostei muito deste desafio.” (aluna L) "Obrigada professora por lançar estes desafios, podem ser uma maneira de incentivar a minha filha a gostar mais desta disciplina.” (mãe L) “Este desafio foi Familiástico!” (aluna Q)

Notou-se ainda alguma permanência na constituição das "equipas respondentes", demonstrando este facto tanto o interesse e envolvimento dos alunos, quanto dos seus familiares: "Este fim de semana excedemo-nos! Eu e a minha filha divertimo-nos imenso na realização das tarefas.” (pai Q) “O pai às vezes está mais ansioso do que a filha!” (mãe Q)

Através desta dinâmica foi possível à investigadora perceber algumas fragilidades das relações familiares, possibilitando-lhe enquanto professora estagiária dar um apoio mais ajustado às necessidades das diferentes crianças, não só ao nível da suas aprendizagens formais, mas também da sua formação social e bem-estar emocional.

Face a todos estes ganhos, esta proposta metodológica respondeu ao seu principal objetivo de criar uma relação mais produtiva entre a escola e a família, tirando-se desta vantagens para todos os intervenientes do processo: alunos, pais e professora.

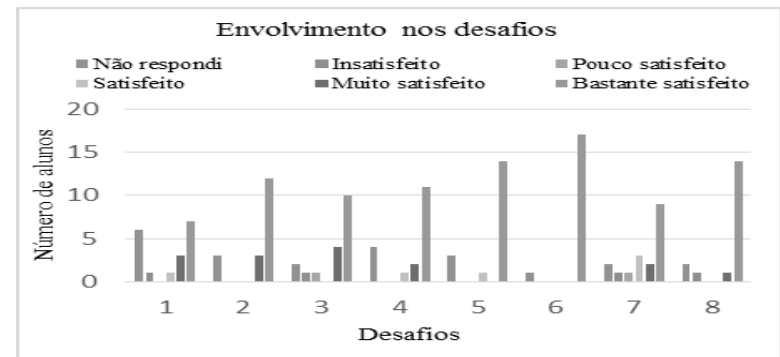

Figura 3. Grau de satisfação dos alunos na realização dos desafios (1-8). 
A implicação dos alunos com os desafios foi analisada nesta investigação através da satisfação com que resolveram as diferentes tarefas e de comentários dos participantes.

Percebeu-se que o desafio 6 foi aquele em que os alunos mais participaram (21) e sobre o qual evidenciaram maior satisfação (Figura 3). Este exigiu muito empenho dos alunos na criação de questões matemáticas, mas foi realizado com motivação pois o produto final constituía um jogo, como qual puderam brincar à matemática uns com os outros.

Relativamente à criatividade, os alunos mostraram-se fluentes e flexíveis, principalmente nos desafios mais abertos. O número de respostas originais foi menor, o que revela a necessidade de se proporem tarefas desafiadoras que possam potenciar a originalidade das crianças. Com o estudo desenvolvido apenas se deu o primeiro passo da caminhada que se prevê longa.

\section{Considerações finais}

No final deste estudo pode dizer-se que foram sendo apresentadas resoluções cada vez mais criativas e diversificadas e tecidos comentários bastante positivos quer às propostas em si, quer relativos à Matemática.

A iniciativa promoveu um contacto semanal entre as famílias e a professora estagiária, e a partilha no blogue fomentou a motivação de alunos e familiares, promovendo a sua participação nos desafios. Estes serviram ainda como meio de envolver os familiares, de forma dinâmica, no processo de ensino-aprendizagem, rompendo com a tradicional imagem do TPC.

Apesar de reduzida no tempo e de acordo com os testemunhos das crianças, das famílias e da professora titular de turma, esta iniciativa revelou-se potenciadora de uma imagem mais positiva da Matemática e um meio de fortificar a relação escola-família.

\section{Referências}

Alencar, E. (1989). A repressão do potencial criador. Psicologia Ciência e Profissão, 9, 3, 11-13.

Almeida, A. N. (2005). O que as famílias fazem à escola... pistas para um debate. Análise Social, XI, $n^{\circ} 176$.

Callender, S., \& Hansen, A. (2004). Home and School: Family-School Partnerships: information and approaches for educators. Em A. S. Canter, L. Z. Paige, M. Roth, I. Romero, \& S. Carrol (Eds.), Helping Children at Home and School II: Handouts for Families and Educators (pp. 25-28). Minnesota: National Association of School Psychologists.

César, M. (2012). O papel das famílias nos processos de aprendizagem matemática dos alunos: caminhos para a inclusão ou retratos de formas (subtis) de exclusão? Interacções, 20, 255-292.

Christenson, S. L., \& Sheridan, S. M. (Eds.). (2001). Schools and Families: Creating essential connections for learning. New York: The Guilford Press.

Epstein, J. L. (2002). School, Family, and Community Patnerships: Caring for the Children We Share. Em J. L. Epstein, M. G. Sanders, B. S. Simon, K.
C. Salinas, N. R. Jansorn, \& F. L. Voorhis, School, Family, and Community partnerships: Your handbook for action (pp. 7-29). California: Corwin Press, SAGE.

Gill, B. P., \& Schlossman, S. L. (2003). A Nation at Rest: The American Way of Homework. Educational Evaluation and Policy Analysis, 25, 3, 319-337.

Henriques, M. E. (2006). Os trabalhos de casa na escola do $1^{\circ}$ ciclo da Luz: Estudo de caso. Interaç̧ões, 2, 220-243.

Moreno, M., Fonseca, L. \& Gonçalves, T. (2012). Envolvimento das Mães no Trabalho de Casa (TPC) de Matemática: Contributo para o Desenvolvimento da Comunicação Matemática. Em Pinto, H., Jacinto, H., Henriques, A., Silvestre, A. Nunes, C. (Org.), Atas do XXIII Seminário de Investigação em Educação Matemática, Simpósio 5: Capacidades Transversais, pp. 595-606. Lisboa: Associação de Professores de Matemática.

Movshovitz-Hadar, N., \& Kleiner, I. (2009). Intelectual courage and mathematical creativity. Em R. Leikin, A. Berman, \& B. Koichu (Eds.), Creativity in Mathematics and Education of Gifted Students (pp. 31-50). Rotterdam: Sense Publishers.

Pehkonen, E. (1997). The State-of-Art in Mathematical Creativity. ZDM: Mathematics Education, pp. 6367.

Ponte, J. P. (2005). Gestão curricular em Matemática. Em GTI (Ed.), O professor e o desenvolvimento (pp. 11-34). Lisboa: APM.

Ponte, J. P. (2009). O novo programa de matemática como oportunidade de mudança para os professores do Ensino Básico. Interacções, 12, 96114.

Roy, J. (1997). Ser, actualmente, pai de um aluno. Em A. Rodrigues-Lopes (Ed.), Problemática da família: Contributo para uma reflexão sobre a família na sociedade actual (pp. 156-165). Viseu: Instituto Politécnico de Viseu.

Sheffield, L. J. (2009). Developing mathematical creativity - Questions may be the answer. Em R. Leikin, A. Berman, \& B. Koichu (Edits.), Creativity in Mathematics and the Education of Gifted Students (pp. 87-100). Rotterdam: Sense Publishers.

Taylor, P. (2009). Challenge in mathematics learning Where to from here? Em R. Leikin, A. Berman, \& B. Koichu (Edits.), Creativity in Mathematics and the Education of Gifted Students (pp. 71-85). Rotterdam: Sense Publishers.

Torrance, E. P., \& Torrance, J. P. (1974). Pode-se ensinar criatividade? (A. Kremnitzer, Trad.) São Paulo: Editora Pedagógica e Universitária.

Vale, I., Pimentel, T., Cabrita, I., Barbosa, A., \& Fonseca, L. (2012). Pattern problem solving tasks as a mean to foster creativity in mathematics. Em T. Y. Tso, Proceedings of the 36th Conference of the International Group for the Psychology of Mathematics Education (Vol. 4, pp. 171-178). Taipei,Taiwan:PME. 